\section{SPREADING SCOURGE}

Many countries lack reliable data to track emerging microbial threats, according to the World Health Organization. In large areas of the world, fewer than five antibiotic-resistant bacteria-drug pairs are monitored.

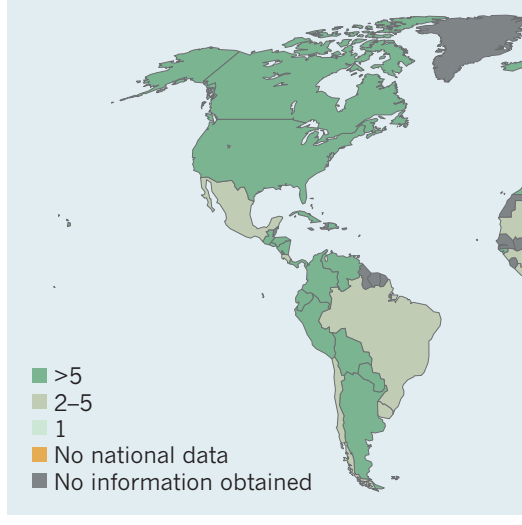

- list includes S. aureus and methicillin, Escherichia coli and cephalosporins, and Klebsiella pneumoniae and carbapenems.

Such problems are compounded by a lack of new antimicrobial drugs in development. This is more than just a problem of future antibiotic supply: pharmaceutical companies' clinical trials of antibiotics were once a valuable source of resistance data for public-health researchers, says Klugman. "Now that we live in a world where there are very few new antibiotics, there is almost none of that support."

As a result, researchers do not know what factors have caused resistance to grow so rapidly in developing nations. For instance, it is not clear to what extent the rise of resistance has been spurred by the use of antibiotics for growth promotion in livestock, or by the release of antibiotics into wastewater by drugmanufacturers in countries such as India. resource," says Ramanan Laxminarayan, the director of the Center for Disease Dynamics, Economics \& Policy (CDDEP) in Washington DC. Yet insisting that antibiotics be prescribed by physicians in nations where poverty is rife and visits to a doctor are a luxury would mean denying many people drugs that they do need.

Meanwhile, in developed countries, inappropriate prescribing can be a problem if physicians bow to pressure from patients. Training pharmacists and educating the public on correct use of antibiotics could go a long way towards curbing resistance around the world, Laxminarayan says.

Solving these problems will require better monitoring of drug resistance, says Stuart Levy, a physician-scientist at Tufts University in Boston, Massachusetts, who heads the nonprofit Alliance for the Prudent Use of Antibiotics. "You can't just go in and scoop up a sample and get results of resistance and think that's the country-wide resistance rate," he says. The WHO report proposes a new global surveillance network, although it is not clear who would pay for it. Levy says that hospitals, nongovernmental organizations and local communities could help to track antibiotic usage and test for resistance with inexpensive, readily available screens.

One thing is clear: new types of antibiotic, although sorely needed, cannot offer a solution on their own. They are likely to be expensive and unaffordable in the developing world. More importantly, says Sumanth Gandra, a CDDEP epidemiologist, it is all but inevitable that new drugs will eventually lose their potency, too. "We'll continue the cycle unless we have new drugs and approach the way we use them differently," says Gandra.

\title{
Avalanche hotspot revealed
}

\section{Study of disaster-prone Russian islands underscores perils of colonizing unfamiliar terrains.}

\section{BY JANE QIU}

$\mathrm{R}$ ussian writer Anton Chekhov noted in 1895 that the strong blizzards on the island of Sakhalin, once home to a Russian penal colony, were a "friend" to the resident convicts, killing several soldiers. The blizzards are also the main cause of avalanches on Sakhalin and the nearby Kuril islands, and an analysis has now revealed the region to have one of the world's deadliest avalanche records (see 'Snow fall').

The death toll in a 100-year period on the Kurils and Sakhalin - a large island in the north Pacific Ocean - exceeds all avalanche-related fatalities in the history of Canada or New Zealand. The study highlights the need for proper avalanche assessment and mitigation measures, such as snow fences.

Until now, the extent of avalanches on the islands had remained elusive because of the their divided history, says Evgeny Podolskiy, a Russian avalanche researcher at the French National Research Institute of Science and Technology for Environment and Agriculture near Grenoble, who led the analysis. Fought over by Japan and Russia during the twentieth century, Sakhalin and the Kuril islands - an archipelago that forms part of the 'ring of fire', a band of intense volcanic activity encircling the Pacific - had no continuous avalanche record. That "has largely hindered the efforts to mitigate avalanche risks", says Podolskiy.

The findings also have implications for the migration of people to mountainous terrains, especially in developing countries, say Podolskiy and his colleagues, who published their study last month in the Journal of Glaciology (E. A. Podolskiy et al. J. Glaciol. 60, 409-430; 2014).

Despite a legacy of limited information exchange between Russia and Japan, Podolskiy was determined to piece together a complete history of avalanches on the islands. After talking to colleagues in Japan, where he did 
E his $\mathrm{PhD}$, Podolskiy found a rare archive. Kaoru Izumi, an avalanche scientist at Niigata University, had a collection of newspaper articles on avalanches that occurred between 1910 and 1945 on the islands, when they were under Japanese control. Izumi had hoped to one day work with Russian scientists.

An astonishing picture emerged from combining and analysing the Japanese and Russian records. Podolskiy, Izumi and their team found that there had been at least 756 fatalities and 238 injuries in 275 avalanches on the islands between 1910 and 2010. The worst avalanche - the deadliest in Soviet history - killed 149 people on Sakhalin in 1945, when it buried a miners' settlement at night.

The study also highlights the danger of small avalanches, says Karl Birkeland, a researcher at the US Forest Service National Avalanche Center in Bozeman, Montana. He says that catastrophic avalanches do not come only in the form of "huge monsters coming down from high mountains over a long distance".

The avalanches that occurred on the islands were mostly on small, gentle slopes with vertical drops of 100-200 metres. It is surprising that this kind of topography could produce such deadly avalanches, says Birkeland.

Mountains on Sakhalin and the Kuril islands are less than 1,600 metres high, and most settlements are concentrated in coastal areas with gently rolling topography. But "the innocent-looking slopes are deceptive", says Podolskiy. The high latitudes and maritime climate mean that the winter is very cold

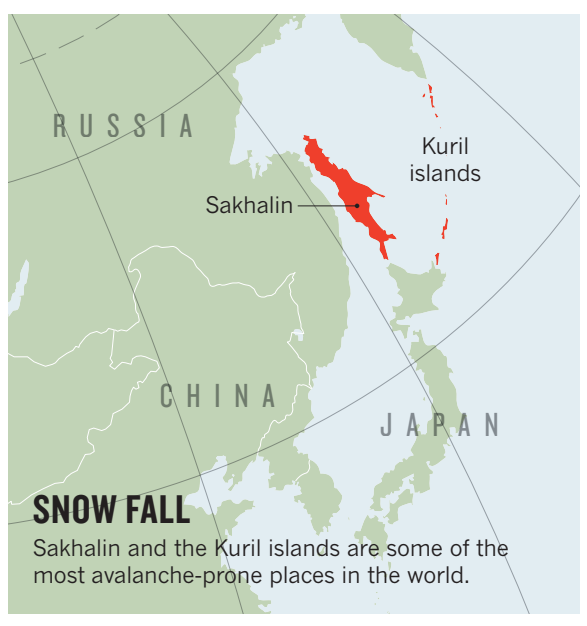

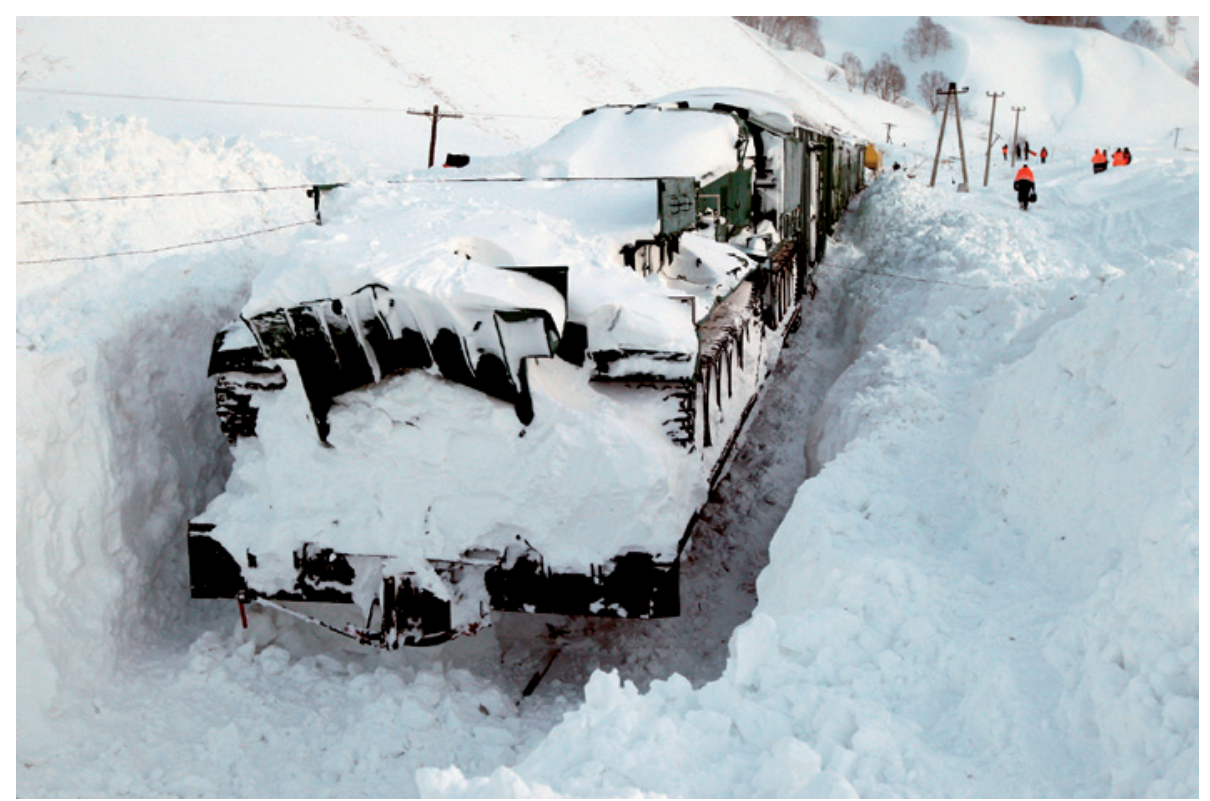

A train buried by an avalanche on the Russian island of Sakhalin in 2010.

and humid, with heavy snow storms for five months a year.

With a large amount of snow in a windswept terrain, "you don't need a big slope to have catastrophic avalanches", says Kouichi Nishimura, an avalanche researcher at Nagoya University in Japan. Early settlements were hidden away from the wind under cliffs with 'snow cornices', large overhangs formed by windswept snow. If these broke away and triggered an avalanche, the destruction could be immense.

The islands' first colonizers "were not aware of the risks and built houses, factories and roads in avalanche-prone areas without proper protection", notes Sergey Sokratov, a snow scientist at the Lomonosov Moscow State University in Russia.

By comparing the avalanche data against population records, the researchers found that periods of high avalanche fatalities - from the 1930 s to the 1960s, for example, when the fatality rate was as high as 60 per 100,000 people per decade - were associated with waves of population influx, rapid industrial development and large-scale deforestation. The team showed a similar correlation on the neighbouring Japanese island of Hokkaido, which was also rapidly colonized in the early twentieth century. The trends underscore the importance of avoiding deforestation, particularly on slopes that are at high risk of snowslides.

Although the decadal avalanche-fatality rate on Sakhalin has since dropped, and was about 1.1 per 100,000 people in $2000-09$ "the findings are still very relevant" because a large part of the region's settlements remain unprotected from avalanche risks, says Nishimura, who is in discussions with Russian colleagues to develop mitigation measures on Sakhalin.

"Historical records are extremely valuable for avalanche mitigation," says Perry Bartelt, a researcher at the Swiss Federal Institute for Snow and Avalanche Research in Davos. In Europe, databases going back more than 300 years are used in planning for disaster mitigation. Such information "is critical for calibrating numerical models to predict how far an avalanche would go at what speed and how much impact it would generate", adds Bartelt.

Sokratov feels that the study has much broader implications as a cautionary tale for people moving to new terrains. "Never rush to build roads and houses without analysing the risks," he says. "With greater awareness and proper mitigation, many lives can be saved from snow avalanches and other natural hazards."

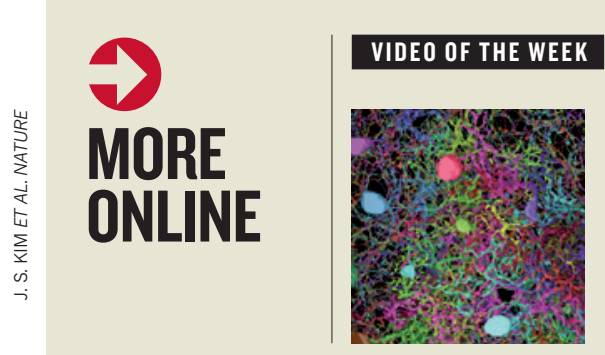

Wiring of the retina reveals how eyes are able to sense motion go.nature. com/nvnwop

\section{MORE NEWS}

- Awareness of speech comes from auditory feedback go.nature.com/ggifuq - Meditation modulates immune responses go.nature.com/ujgtjs

- Insecticide protects Galapagos birds from parasite go.nature.com/glffiq

\section{NATURE PODCAST}

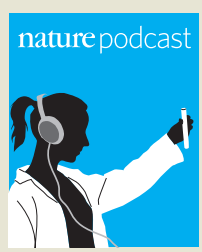

Retina connectomics, whole-Universe simulation, and artificial DNA base pairs nature.com/ nature/podcast 